\title{
Salt seeking by means of food and fluid selection in adrenalectomized rats
}

\author{
DOUGLAS L. GRIMSLEY and ELIZABETH C. STARNES \\ University of North Carolina at Charlotte, Charlotte, North Carolina 28223
}

\begin{abstract}
An experiment involving several changes in the salt content of food and solutions investigated the generality of salt-seeking behavior in adrenalectomized rats. Salt-solution intake varied as a function of $\mathrm{NaCl}$ concentration. The intake of sodium is relatively unaffected by the concentration of $\mathrm{NaCl}$ in the food as long as $\mathrm{NaCl}$ in solution is available. But when the salt solution is removed, salt seeking and sodium regulation takes place by way of salt in the food.
\end{abstract}

It has been demonstrated repeatedly that rats depleted of sodium through adrenalectomy, sodium deficient diets, or by other artificial means, show a strong preference for the needed substance. Rats in a free-choice situation prefer sodium chloride solution of various concentrations to tap water. The response of salt seeking following adrenalectomy is a highly reliable one, and will persist in spite of irradiation (Cullen, 1969), established sugar (Grimsley, 1970) or saccharine (Grimsley \& Fisher, 1967) preference, and preoperative aversion to similar substances (Frumkin, 1971).

Studies on salt seeking in rats when the salt was in food, not solution, have further explored the generality of this consummatory behavior. Fregly, Harper, and Radford (1965) studied the $\mathrm{NaCl}$ intake of salt-deprived rats when given a choice between distilled water and a solution while the salt content of the food was varied. The intake of $\mathrm{NaCl}$ by drinking (solution) was not affected by dietary salt levels, even when the concentration of salt in the food reached $6 \%$. Those results support the idea that $\mathrm{NaCl}$ regulation in rats occurs via salt in solution only and not by $\mathrm{NaCl}$ levels in food. More recently, Grimsley (1973) showed that the adrenalectomized (ADX) rat will seek out and consume $\mathrm{NaCl}$ in sufficient quantities to maintain internal sodium levels when the only salt available is in the food. Under diets which differed in salt content, the ADX rats selected salty over plain food, maintained their body weights, and showed no adverse symptoms.

The present study was designed to further elaborate the phenomenon of salt seeking to determine whether ADX rats, when given $\mathrm{NaCl}$ in both food and solution, prefer to regulate consumption exclusively by one form or by a combination of the two.

\section{METHOD}

Subjects

The 15 male Sprague-Dawley rats (Flow Laboratories, Dublin, Virginia) used in this experiment averaged $83 \mathrm{~g}$ at the start of the experiment.

\section{Apparatus}

All rats were fed ground Purina Lab Chow presented in two glass food cups which were attached alternately with two graduated glass $100-\mathrm{ml}$ drinking tubes to the front of each cage. One cup contained plain food and the other salty food: $3 \mathrm{~g}$ of $\mathrm{NaCl}$ added per $100 \mathrm{~g}$ of food, thoroughly mixed. One drinking tube contained tap water, while the other contained salt water: either $3 \% \mathrm{NaCl}(3 \mathrm{~g}$ of $\mathrm{NaCl}$ per $100 \mathrm{ml}$ of solution) or $6 \%$ $\mathrm{NaCl}$, similarly mixed. Position of the $\mathrm{NaCl}$ and plain food solutions were alternated daily to control for position preferences.

\section{Procedure}

For 10 preoperative days, all rats were given ad-lib access to both salty and plain food, water, and a $3 \% \mathrm{NaCl}$ solution. Food and fluid intake and body weight were recorded daily.

Eight animals were randomly assigned to the ADX group and seven to the sham group (sham surgery consisted of bilateral incisions and exposure of the adrenals, but they were not removed). Both groups continued to receive both salty and plain food, and salty and plain water for the 51 postoperative days.

On Postoperative Day 18, all animals received an intraperitoneal injection of a $3 \% \mathrm{NaCl}$ solution in a dosage of $12 \mathrm{mg} / \mathrm{kg}$. Food and solution intake were measured at regular intervals for a 24-h period following the injection.

The $\mathrm{NaCl}$ concentrations of the food and drinking solution were raised to $6 \%$ on Postoperative Day 25 . After 7 days, the concentrations were returned to $3 \%$ for 6 additional days. While food salt concentration remained at $3 \%$, the $\mathrm{NaCl}$ solution was removed (Postoperative Day 38) for a 7-day period and returned for the following 6 days.

To verify adrenalectomy, all salt was removed and mortality was recorded for a 14-day period. One "adrenalectomized" animal survived the 2-week salt-free period so its data were excluded.

\section{RESULTS}

One of the ADX rats died during surgery (and one was eliminated for failure to confirm adrenalectomy), leaving six ADX animals and seven which received sham surgery. Preoperatively, all animals showed a marked preference for the plain food and water, and both groups consumed similar amounts.

The ADX group showed an immediate and sustained increase in the consumption of $\mathrm{NaCl}$ solution postoperatively compared to the sham group, as shown in Figure 1. They consumed more salt solution than sham controls over the entire 51-day period $[F(1,12)=164.36, p<.01]$. 


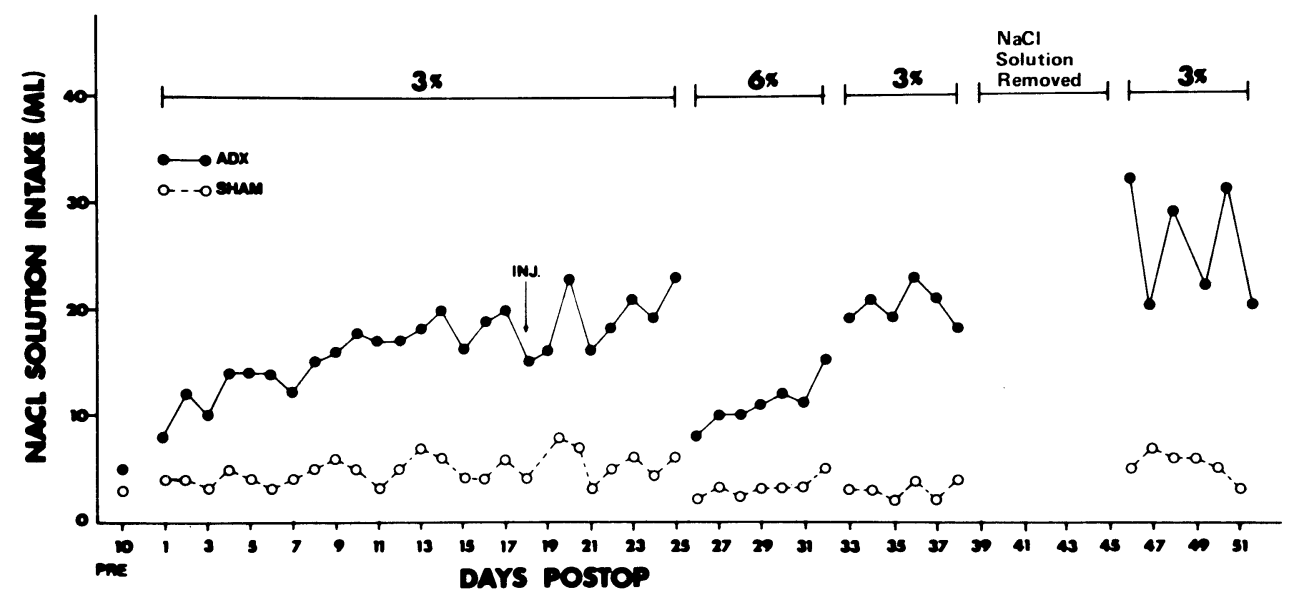

Figure 1. Mean $\mathrm{NaCl}$ solution intake for the final preoperative and 51 postoperative days.

When the salt concentration of the solution was doubled to $6 \%$, consumption decreased from a mean of $20 \mathrm{ml}$ for the $3 \%$ condition to a mean of 13 for the $6 \%$ condition. When the concentration was returned to $3 \%$, the mean consumption returned to $20 \mathrm{ml}$. There remained a significant difference between groups during the last 5 days of the $6 \%$ consumption period used in the analysis $[F(3,36)=$ $109.98, \mathrm{p}<.01]$. The $\mathrm{NaCl}$ solution was removed for 7 days. When it was returned, the ADX animals dramatically increased their consumption for the first day $(32 \mathrm{ml})$ and gradually returned to the level of intake which they showed prior to the removal of the salt solution. Again, there was a significant difference between the ADX and sham groups during the last 5 days $[F(3)=381.20, p<.01]$.

The salt injection all animals received on Day 18 did not reduce the salt water intake of the ADX animals on the day of injection or on the day after. They did increase their plain water intake significantly $[t(5)=21.0, p<.05]$ in order to dilute the extra salt provided by the injection. The intake of food was not significantly affected, though it was reduced the day of injection. The sham animals significantly reduced their salt-water intake $[\mathrm{t}(6)=3.38, \mathrm{p}<.01]$ during the $24 \mathrm{~h}$ following the injection but did not change their plain food, salty food, or water intake. They returned to their baseline intake of salt water the day after the injection.

Both groups consumed similar amounts of $\mathrm{NaCl}$ food over 38 postoperative days, when the $\mathrm{NaCl}$ solution was also available, as shown in Figure 2. The ADX rats' intake of salty food remained relatively constant in spite of a salt injection and changes in salt solution concentration. For example, even though the concentration was doubled to $6 \%$, intake remained at about a mean of $2 \mathrm{~g}$ per day. When the $\mathrm{NaCl}$ solution was removed on Day 38 , the ADX rats showed a dramatic increase in $\mathrm{NaCl}$ food intake, while the intake for the sham animals was not altered. The differences between groups over the last 5 of the 7-day measurement period without

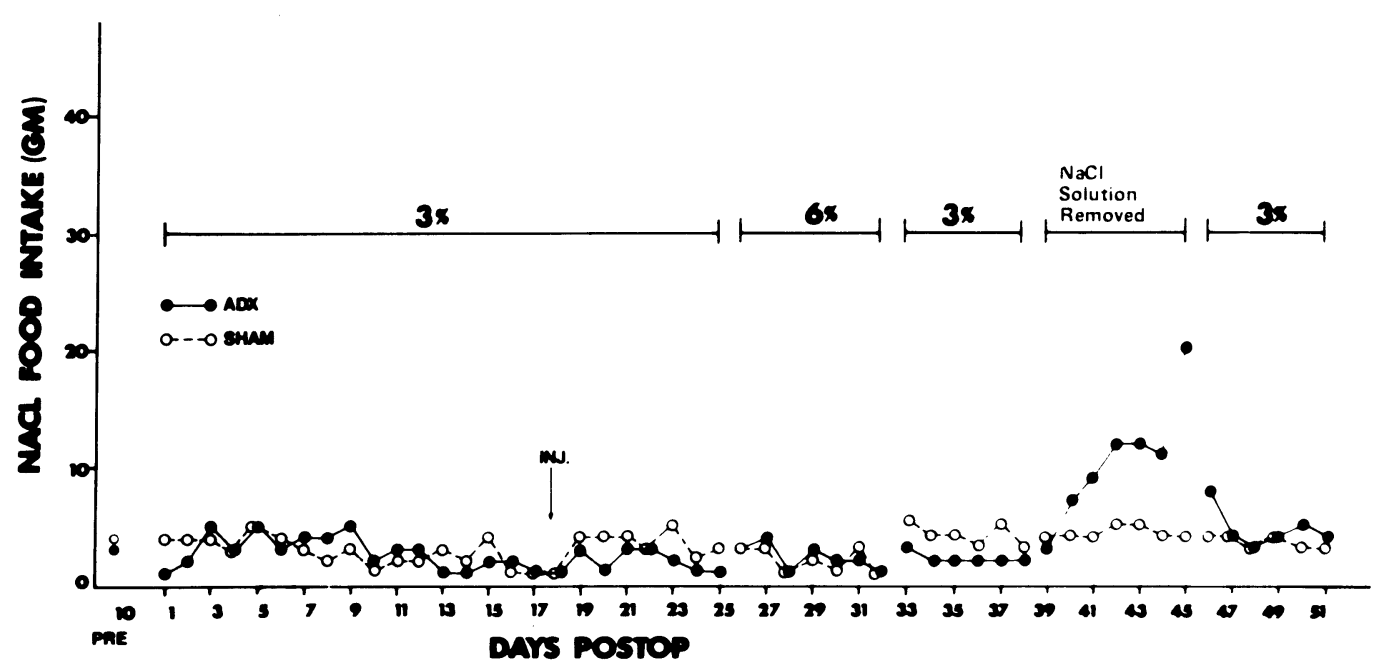

Figure 2. Mean $\mathrm{NaCl}$ food intake for the final preoperative and 51 postoperative days. 


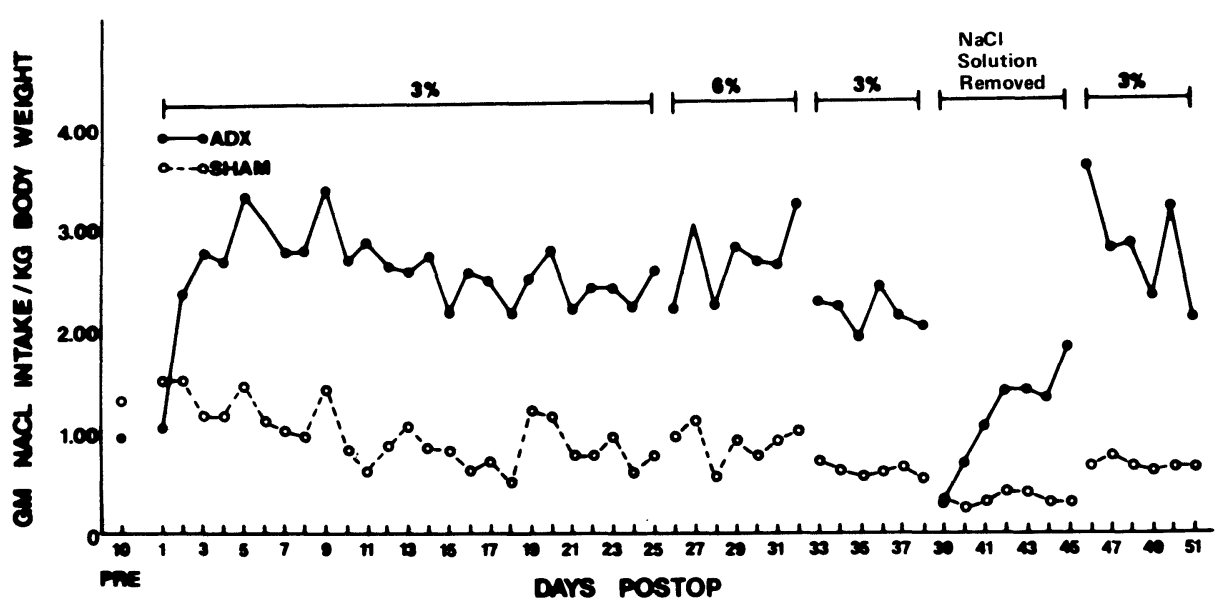

Figure 3. Mean $\mathrm{NaCl}$ intake for final preoperative and 51 postoperative days.

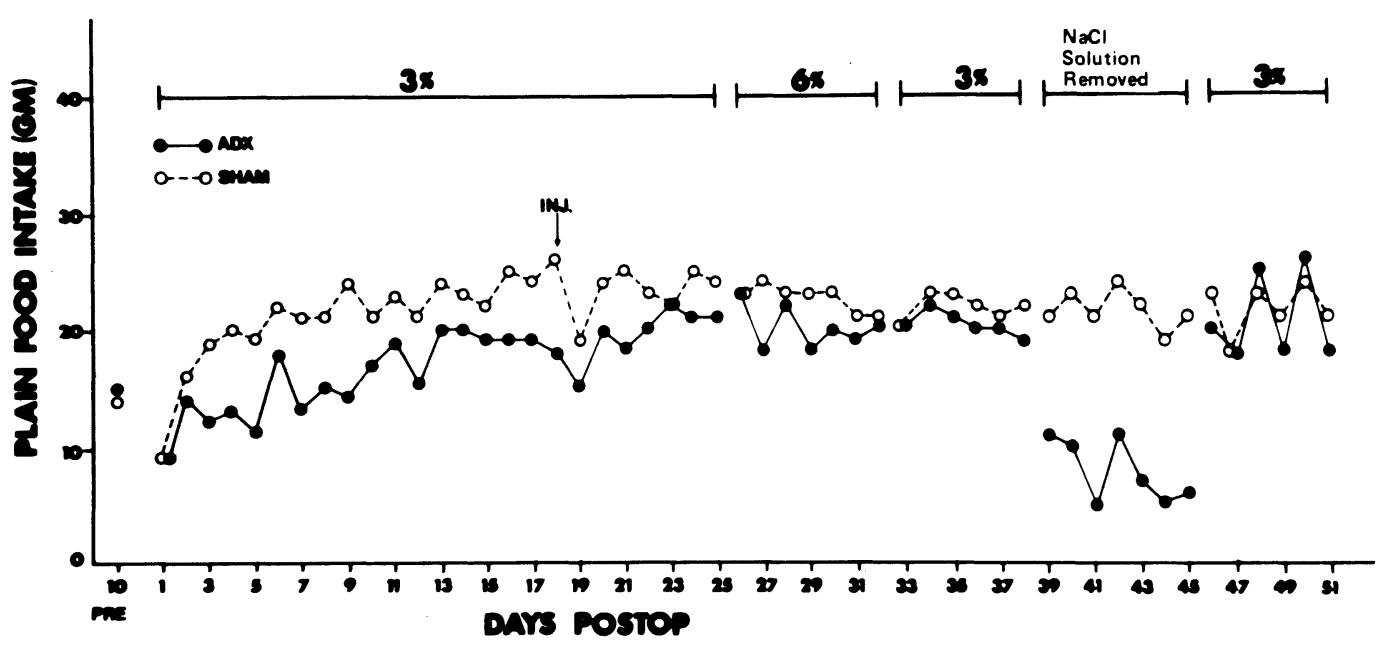

Figure 4. Mean plain food intake for the final preoperative and 51 postoperative days.

$\mathrm{NaCl}$ fluid was highly significant $[\mathrm{F}(3,36)=49.68$, $\mathrm{p}<.01]$. When the $\mathrm{NaCl}$ fluid was again made available, the ADX rats stopped eating salty food and returned to the solution to obtain salt. During the last 5 days of the experiment (Days 47-51), there again was no difference in $\mathrm{NaCl}$ food consumption $(p>.05)$ between the two groups.

Figure 3 shows the actual amount of $\mathrm{NaCl}$ consumed $(\mathrm{g} / \mathrm{NaCl} / \mathrm{kg}$ of body weight) over the course of the study. It can be seen that the ADX rats maintained a rather constant $\mathrm{NaCl}$ intake under various conditions. The intake of $\mathrm{NaCl}$ was approximately $3 \mathrm{~g} / \mathrm{kg}$ of body weight during all treatments except when the salt solution was removed. When the only available salt was in the food, $\mathrm{NaCl}$ intake fell dramatically but approached the average level of intake within 7 days.

The data for plain food intake, shown in Figure 4, also reflects the data shown for salty food. There were no significant differences between the groups until Days 38-45 postoperatively, when the salt solution was removed. Plain food intake dropped dramatically when the salty food intake increased, and the groups were significantly different over Days 41-45 $[\mathrm{F}(3,36)=264.37, \mathrm{p}<.01]$. When the salt solution was again available, both groups again consumed similar amounts of plain food.

Both groups showed an increase in mean body weight over the 51 postoperative days, but the ADX animals remained significantly lighter throughout the course of the postoperative period $[F(1,12)=15.51$, $\mathrm{p}<.01]$. The ADX rats more than doubled their weights over the postoperative period. The only major setback in weight gain for the ADX animals occurred when the salt solution was removed. Water intake was similar for both groups during the course of the experiment.

\section{DISCUSSION}

When given access to salt, the ADX rat consumes sufficient amounts to maintain his body weight and 
prevent the symptoms associated with an adrenal insufficiency. After approximately 12 days, salt consumption tends to level off, indicating that sufficient $\mathrm{NaCl}$ is being consumed to maintain a homeostatic state. The pattern obtained in this study is consistent with the results of Epstein and Stellar (1955) and Grimsley (1973) who described the pattern of increasing specific hunger for salt following adrenalectomy.

When salt is available in both food and fluid, the ADX animals prefer to regulate by drinking. This is shown by the fact that the intake of salty food was not statistically different for the ADX and sham animals during the first 38 postoperative days, while the salty solution intake was significantly greater for the ADX animals. It was only when the $\mathrm{NaCl}$ solution was removed during Days 39-45 that the $\mathrm{NaCl}$ food intake differed significantly for the two groups.

The fact that consumption of salty solution varied as a function of $\mathrm{NaCl}$ concentration in the food and solution attests to the fact that ADX animals were regulating internal salt levels. For example, the percentage of the total solution intake that was salty was reduced by about one-half when the salt content was doubled from $3 \%$ to $6 \%$. When the salt concentration was returned to $3 \%$, the intake of salty solution doubled.

When the salty solution was removed, the ADX animals did increase their intake of salty food and ate sufficient amounts to prevent sodium deficiency. The increase in salty food consumption increased steadily during the 7 days the salty solution was not available. For example, on Day 38, the last day the salty solution was available, the percentage of food which was salty was $10 \%$ for the ADX group. Intake had increased to about $40 \%$ salty food by Day 40 and to almost $80 \%$ by Day 45 . When the salt solution was restored, salty food intake returned to its previous low level within 2 days with a compensatory large intake of salt solution. The intake of sodium is relatively unaffected by the concentration of $\mathrm{NaCl}$ in the food as long as $\mathrm{NaCl}$ in solution is available. However, if $\mathrm{NaCl}$ solution is not available, then regulation is accomplished through the salty food.

These results support and elaborate the findings of Bolles, Sulzbacher, and Arant (1964) and Grimsley (1973) that ADX rats can regulate salt intake by means of food. When given the choice, salt balance is maintained by means of fluid intake. But when salt in solution is not available, ADX rats will seek salt in food and consume it in sufficient quantities to prevent salt imbalance. When the concentration of salt in the food is increased or decreased, consumption decreases and increases to maintain a relatively stable salt intake level.

These findings are not in agreement with Fregly et al. (1965), who concluded that sodium-deficient rats do not regulate by way of salt in the diet. In their study, the sodium deficiency was created by feeding a sodium-deficient diet, not by adrenalectomy. In some cases, their rats were on the sodiumfree diet for only 5 days, hardly the extreme deficit produced by adrenalectomy. Their rats were not forced to obtain $\mathrm{NaCl}$ from the food, since it was also available in solution form at the same time. Grimsley (1973) showed that rats can regulate when the only available salt is in the food. The present study shows that, consistent with Fregly et al. (1965), rats prefer to regulate by way of salt in solution not food. But when the salt solution is removed, regulation takes place by way of salt in the food.

These results support and extend the general findings of salt seeking by ADX rats. Given access to salt, ADX rats will regulate by consuming salt in solution or in food and maintain internal sodium levels.

\section{REFERENCES}

Bolles, R. C., Sulzbacher, S. I., \& Arant, H. Innateness of the adrenalectomized rat's acceptance of salt. Psychonomic Science, 1964, 1, 21-22.

Cullen, J. W. Modification of salt-seeking behavior in the adrenalectomized rat via gamma-ray irradiation. Journal of Comparative and Physiological Psychology, 1969, 68, 524-529.

Epste in, A. E., \& Stellar, E. The control of salt preference in the adrenalectomized rat. Journal of Comparative and Physiological Psychology, 1955, 48, 167-172.

Fregly, M. J., HARPer, J. M., JR., \& Radford, E. P., JR. Regulation of sodium chloride intake by rats. American Journal of Physiology, 1965, 209, 287-292.

Frumkin, K. Interaction of $\mathrm{LiCl}$ aversion and sodium-specific hunger in the adrenalectomized rat. Journal of Comparative and Physiological Psychology, 1971, 75, 32-40.

GrimsLeY, D. L. Salt seeking in the adrenalectomized rat with an established sugar preference. Journal of Comparative and Physiological Psychology, 1970, 71, 284-289.

GRIMSLEY, D. L. Salt seeking by food selection in adrenalectomized rats. Journal of Comparative and Physiological Psychology, 1973, 82, 261-267.

Grimsley, D. L., \& Fisher, L. E., JR. Preoperative saccharine experience and postoperative fluid preference in adrenalectomized rats. Psychonomic Science, 1967, 9, 299-300.

(Received for publication March 13, 1979; revision accepted August 6, 1979.) 